\title{
Chaotic Behavior in a Switched Dynamical System
}

\author{
Fatima El Guezar1, 2 and Hassane Bouzahir ${ }^{3}$ \\ ${ }^{1}$ Laboratoire Toulousain des Technologies et Ingénierie des Systèmes (LATTIS), INSA, 135 Avenue de Rangueil, \\ 31077 Toulouse Cedex 4, France \\ ${ }^{2}$ LabSIV-FS, University Ibn Zohr, P. O. Box 28/S, Agadir 80000, Morocco \\ ${ }^{3}$ ESSI, ENSA, University Ibn Zohr, P. O. Box 1136, Agadir 80000, Morocco
}

Correspondence should be addressed to Fatima El Guezar, fatima.el_guezar@insa-toulouse.fr

Received 4 September 2007; Revised 1 January 2008; Accepted 6 February 2008

Recommended by Igor Kotenko

We present a numerical study of an example of piecewise linear systems that constitute a class of hybrid systems. Precisely, we study the chaotic dynamics of the voltage-mode controlled buck converter circuit in an open loop. By considering the voltage input as a bifurcation parameter, we observe that the obtained simulations show that the buck converter is prone to have subharmonic behavior and chaos. We also present the corresponding bifurcation diagram. Our modeling techniques are based on the new French native modeler and simulator for hybrid systems called Scicos (Scilab connected object simulator) which is a Scilab (scientific laboratory) package. The followed approach takes into account the hybrid nature of the circuit.

Copyright ( 2008 F. El Guezar and H. Bouzahir. This is an open access article distributed under the Creative Commons Attribution License, which permits unrestricted use, distribution, and reproduction in any medium, provided the original work is properly cited.

\section{Introduction}

Hybrid dynamical systems (HDSs) have attracted considerable attention in recent years. HDS arise from the interaction between continuous variable systems (i.e., systems that can be described by a difference or differential equation) and discrete event systems (i.e., systems where the state transitions are initiated by events that occur at discrete time instants). Switched piecewise linear systems are an important class of hybrid systems that are simple and can have very rich and typical nonlinear dynamics such as bifurcations and chaos. As example, DC-DC switching converters are switched piecewise linear systems [1]. The three basic power electronic converters buck, boost, and buck-boost are variable structure systems that are highly nonlinear. This kind of piecewise model may present nonlinear phenomena such as bifurcations and chaos. The study of nonlinear dynamics of DC-DC converters started in 1984 by Brockett's and Wood's research [2]. Since then, chaos and nonlinear phenomena in power electronic circuits have stolen the spotlight and have attracted the attention of different research groups. Different nonlinear phenomena were investigated such as flip bifurcation or period doubling and its related route to chaos $[3-5]$ or quasiperiodicity route to chaos $[6,7]$ as well as border collision bifurcation $[1-3,6-16]$. There are many modeling techniques, programming languages, and design toolsets for HDS. To model and simulate our HDS, we use Scicos (Scilab connected object simulator) which is a Scilab package for modeling and simulation of dynamical systems including both continuous and discrete time subsystems $[17,18]$. Scilab (scientific laboratory) is a scientific software package for numerical computations that provides a powerful open computing environment for engineering and scientific applications [10]. It has been developed at INRIA and ENPC and is freely available for download. This paper aims to study and analyze some dynamic phenomena that can occur in the voltage-mode controlled buck converter. We also show from Scicos simulations that variation of the voltage input can lead to a particular route to chaos. In Section 2, the general equation of a hybrid dynamical system is briefly recalled. In Section 3, we explain the operation of the voltage-mode controlled buck converter. Then, we introduce the state equations of the circuit in question. In Section 4, we comment on the obtained Scicos simulations. We end by some concluding remarks.

\section{Hybrid Dynamical System}

The evolution of an autonomous hybrid dynamical system can be described by [19] 


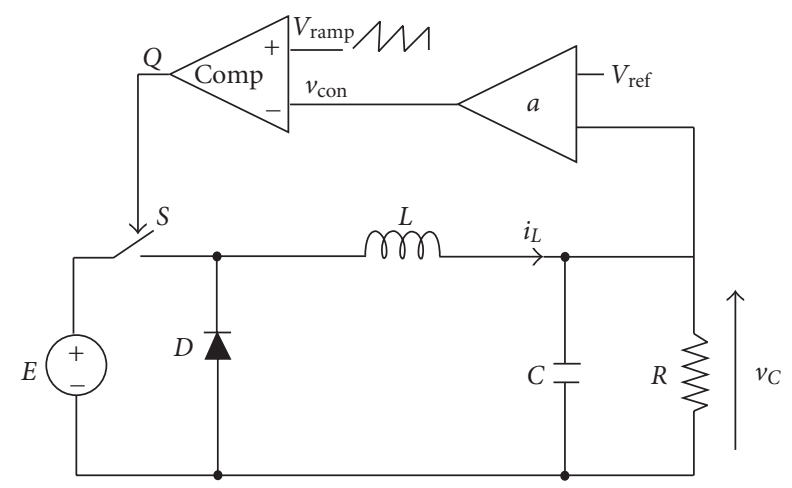

Figure 1: Voltage-mode controlled buck converter.

$$
\begin{aligned}
& \dot{x}(t)=f(x(t), q(t)), \quad x\left(t_{0}\right)=x_{0}, \\
& q(t)=e\left(x(t), q\left(t^{-}\right)\right), \quad q\left(t_{0}\right)=i_{0},
\end{aligned}
$$

where $x(t)$ is the continuous state vector, $q(t) \in Q=$ $\left\{1, \ldots, n_{q}\right\}$ denotes the discrete state, and $q\left(t^{-}\right)$is the previous discrete state. The state space is $H=\mathbb{R}^{n} \times Q$, and the initial state is supposed belonging to the set of initial conditions $\left(x_{0}, i_{0}\right) \in H_{0} \subseteq H$. The function $e: \mathbb{R}^{n} \times Q \rightarrow Q$ describes the change of the discrete state. The change from one distinct discrete state to another is called a transition or a switch. A transition between two states $i$ and $j$ occurs if $x(\cdot)$ reaches the switch set $S_{i, j}: S_{i, j}=\{x: e(x, i)=$ $j\}$. Among important classes of hybrid systems, there are piecewise linear systems that are described by

$$
\dot{x}(t)=f_{q}(x)=A(q) x(t)+B(q),
$$

where $A(q) \in \mathbb{R}^{n \times m}$ and $B(q) \in \mathbb{R}^{n}$ are matrices depending on $q$.

\section{Voltage-mode Controlled Buck Converter}

\subsection{Operation of Voltage-mode Controlled Buck Converter}

A voltage feedback buck converter is represented in Figure 1. It consists of a basic RLC circuit, a diode, and a switching element $S$. The aim of the circuit is to maintain a desired voltage, across the load resistance $R$, lower than the input voltage $E$. This can be realized by the relieve of feedback PWM control. The PWM control of a switched converter is achieved by obtaining a control voltage $v_{\text {con }}(t)$, as a linear combination of the output capacitor voltage $v_{C}(t)$ and a reference signal $V_{\text {ref }}$ in the form of

$$
v_{\mathrm{con}}(t)=a\left(v_{C}(t)-V_{\mathrm{ref}}\right)
$$

where $a$ is the gain of the error amplifier. The control voltage is compared with an externally generated sawtooth wave $V_{\text {ramp }}(t)$ given by

$$
v_{\text {ramp }}(t)=V_{L}+\left(V_{U}-V_{L}\right) \frac{t}{T} \quad t \in[0, T] .
$$

The output of this comparator is used to determine the state of the switch $\mathrm{S}$, in such way that $\mathrm{S}$ is off when $v_{\text {con }}(t) \geq$ $v_{\text {ramp }}(t)$ and $S$ is on when $v_{\text {con }}(t)<v_{\text {ramp }}(t)$.

\subsection{State Equations}

When operating in continuous conduction mode (CCM), two switch states can be identified as follows:

(i) switch off and diode on;

(ii) switch on and diode off.

Whether the switch is on or off, the buck converter can always be described as a second-order linear system, whose states are the voltage $v_{C}$ across the capacitor, and the current $i_{L}$ along the inductor. The general equation that models operation of the buck converter takes the form

$$
\dot{x}(t)=f_{q}(x)=A(q) x(t)+B(q), \quad \text { with } q \in Q=\{1,2\} .
$$

For $q=1$ and $q=2$, we obtain the following two systems of differential equations:

$$
\begin{aligned}
& S_{\text {off }}: \dot{x}(t)=f_{1}(x)=A x(t)+B_{1}, \\
& S_{\text {on }}: \dot{x}(t)=f_{2}(x)=A x(t)+B_{2},
\end{aligned}
$$

where

$$
A=\left(\begin{array}{cc}
\frac{-1}{R C} & \frac{1}{C} \\
\frac{-1}{L} & 0
\end{array}\right), \quad B_{1}=\left(\begin{array}{l}
0 \\
0
\end{array}\right), \quad B_{2}=\left(\begin{array}{c}
0 \\
\frac{E}{L}
\end{array}\right),
$$

and $x=\left(\begin{array}{l}v_{c} \\ i_{L}\end{array}\right)$ is the vector of the state variables.

The border function is given by

$$
\begin{aligned}
\beta(x, t) & =v_{\mathrm{con}}(t)-v_{\mathrm{ramp}}(t) \\
& =a v_{c}(t)-a V_{\mathrm{ref}}-V_{L}-\left(V_{U}-V_{L}\right) \frac{t}{T}, \quad \text { for } t \in[0, T] .
\end{aligned}
$$

Therefore, the switching sections of each subsystem $S_{\text {on }}$ and $S_{\text {off }}$ are given by

$$
\begin{aligned}
& \beta_{\text {on }, \text { off }}=\left\{(x, t) \in \mathbb{R}^{2} \times \mathbb{R}: \beta(x, t) \geq 0\right\}, \\
& \beta_{\text {off,on }}=\left\{(x, t) \in \mathbb{R}^{2} \times \mathbb{R}: \beta(x, t)<0\right\} .
\end{aligned}
$$

The buck converter in CCM switches between two systems $S_{\text {on }}$ and $S_{\text {off }}$ if the state reaches the switching sections $\beta_{\text {on,off }}$

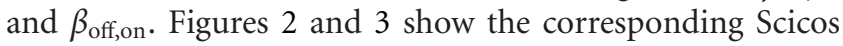
schematic diagram and the transition diagram, respectively.

\subsection{Simulation Results and Comments}

We choose the parameter values: $L=30 \mathrm{mH}, T=400$ microseconds, $R=22 \Omega, C=47 \mu \mathrm{F}, a=8.4, V_{\text {ref }}=11.3 \mathrm{~V}$, $V_{L}=3.8 \mathrm{~V}$, and $V_{U}=8.2 \mathrm{~V}$. We consider the input voltage $E=30 \sim 47 \mathrm{~V}$ as a parameter of bifurcation. By varying $E$, the circuit changes its qualitative behavior from a stable periodic system to another situation that exhibits chaos. At first, using 


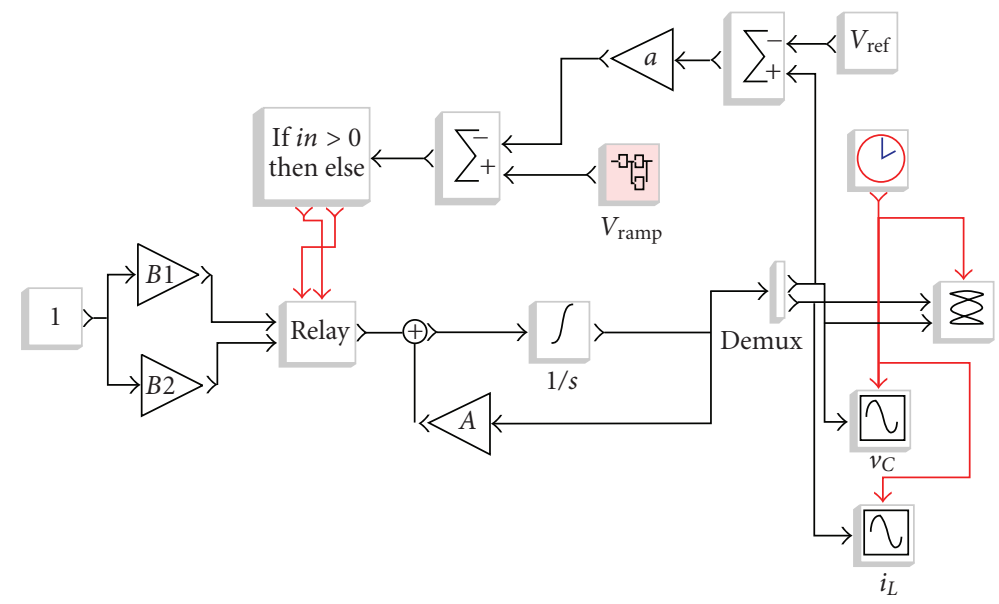

Figure 2: Scicos schematic diagram.

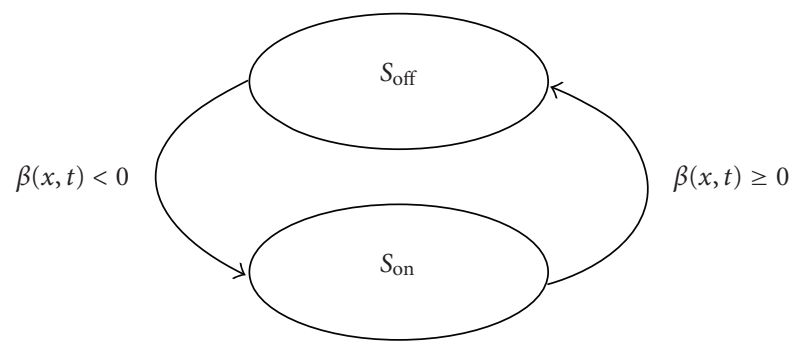

Figure 3: Transition diagram of the buck converter.

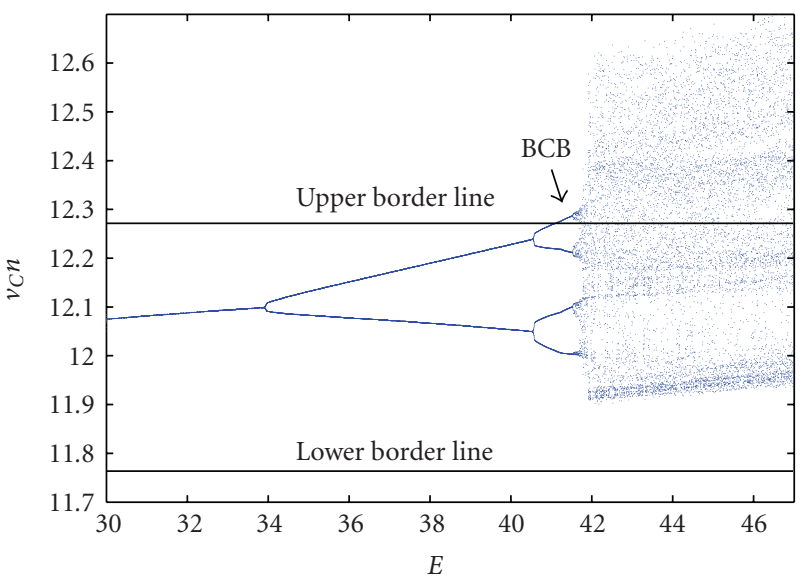

Figure 4: Bifurcation diagram.

Scicos we draw the one-parameter bifurcation diagram given in Figure 4 where the input voltage $E$ is the bifurcation parameter and the sampled $v_{C}$ is the variable. By increasing $E$, we observe at first glance that the displayed diagram (see Figure 4) shows a period doubling route to chaos. However, after a clear 4- $T$ periodic operation, instead of appearance of an immediate 8-T periodic operation, the system follows a 7-T periodic operation. This means that border collision bifurcation comes into play and interrupts the normal period doubling cascade. Here, this type of bifurcation is

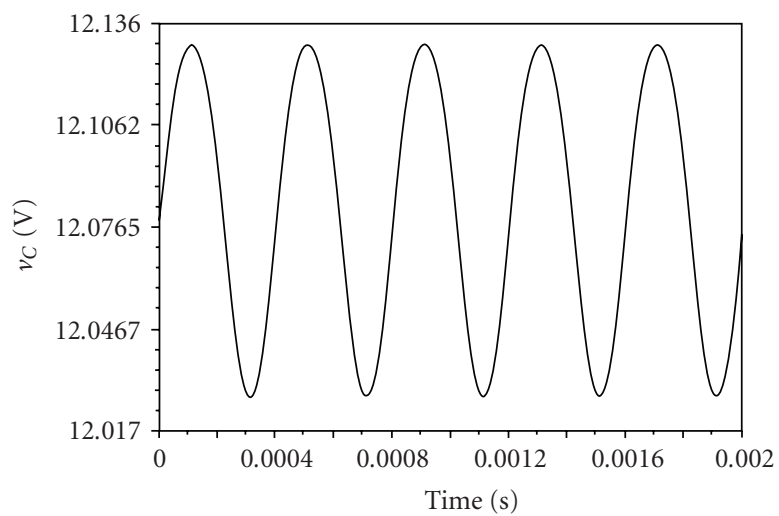

Figure 5: Fundamental periodic operation. $(E=30 \mathrm{~V})$ : time waveform of the capacitor voltage.

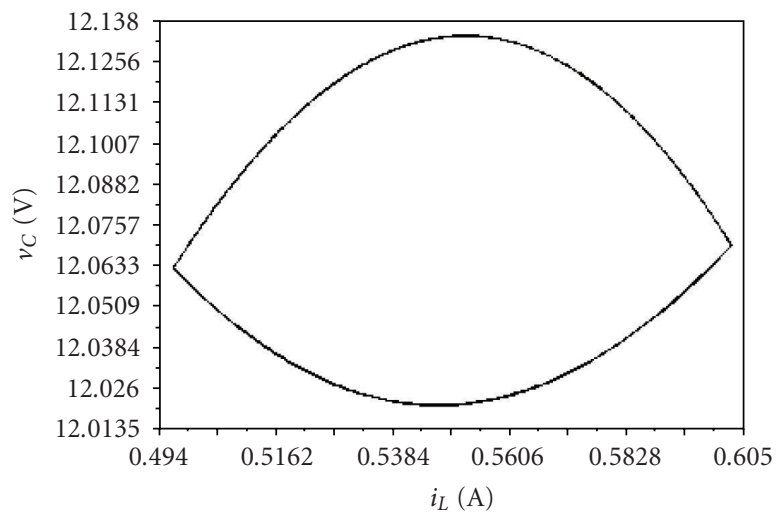

Figure 6: Fundamental periodic operation. $(E=30 \mathrm{~V})$ : phase plane.

characterized by the intersection of the bifurcation diagram with the upper border line defined by

$$
v_{c}=V_{\text {ref }}+\frac{V_{U}}{a} .
$$




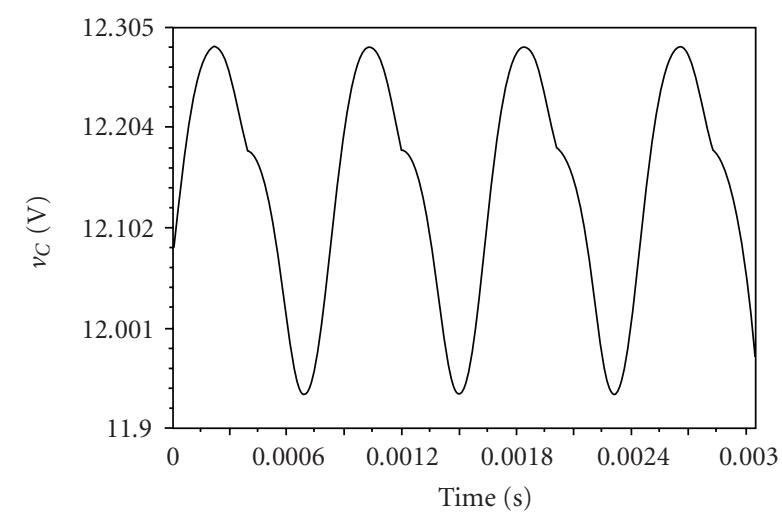

Figure 7: $2-T$ subharmonic operation. $(E=37.5 \mathrm{~V})$ : time waveform of the capacitor voltage.

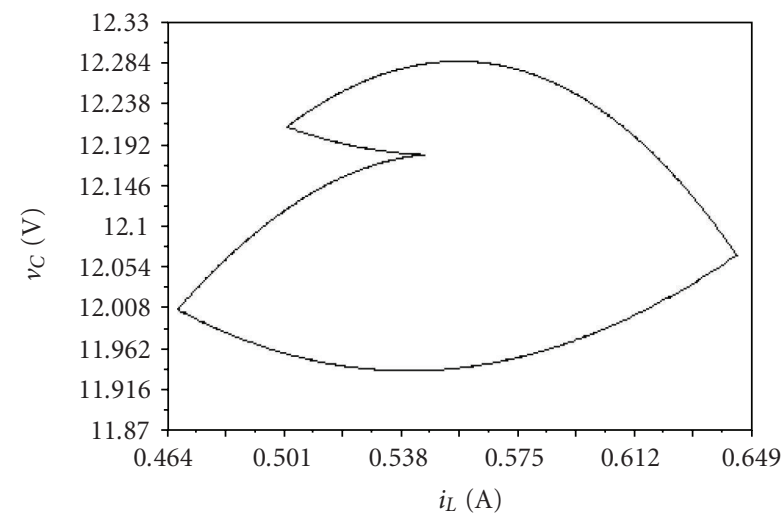

FIgURE 8: 2-T subharmonic operation. $(E=37.5 \mathrm{~V})$ : phase plane.

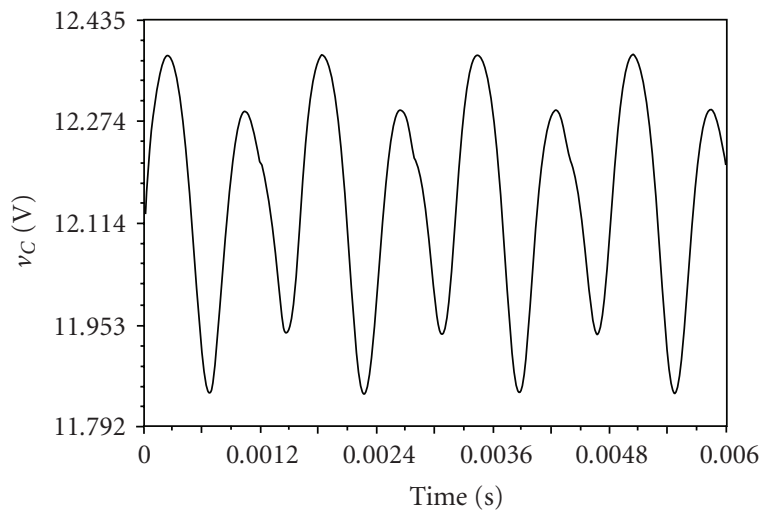

Figure 9: 4- $T$ subharmonic operation. $(E=41 \mathrm{~V})$ : time waveform of the capacitor voltage.

Figure 4 shows clearly the occurrence of this phenomenon at around the critical value $E_{c}=41.45 \mathrm{~V}$.

For different increasing values of $E$, we give the capacitor voltage wave form $v_{C}$ and its corresponding phase plane $v_{C}-i_{L}$.

By choosing $E=30 \mathrm{~V}$, we get a fundamental periodic operation. This periodic regime is possible just for small

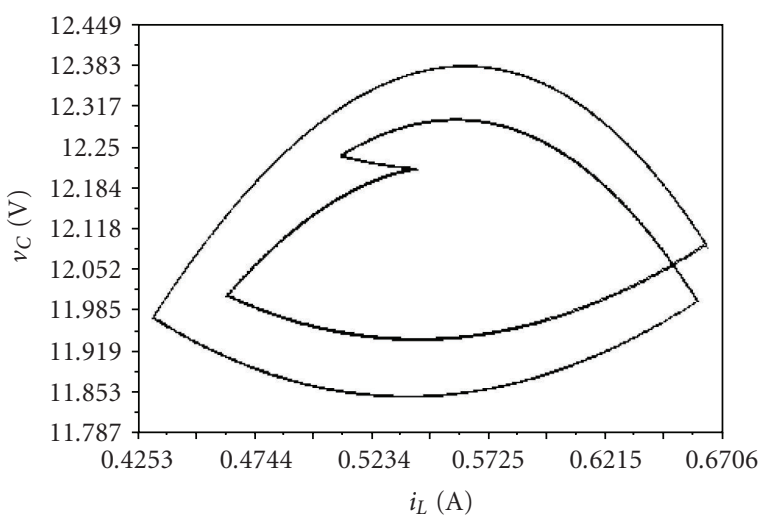

FIgURE 10: 4-T subharmonic operation. $(E=41 \mathrm{~V})$ : phase plane.

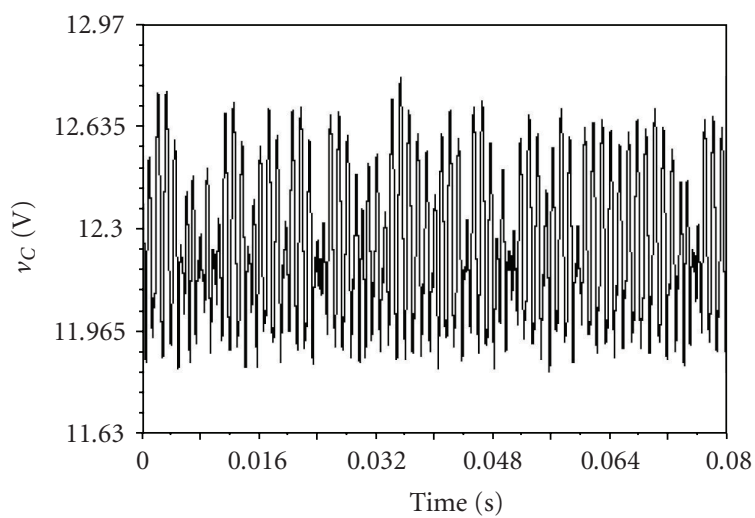

Figure 11: Chaotic regime. $(E=46.5 \mathrm{~V})$ : time waveform of the capacitor voltage.

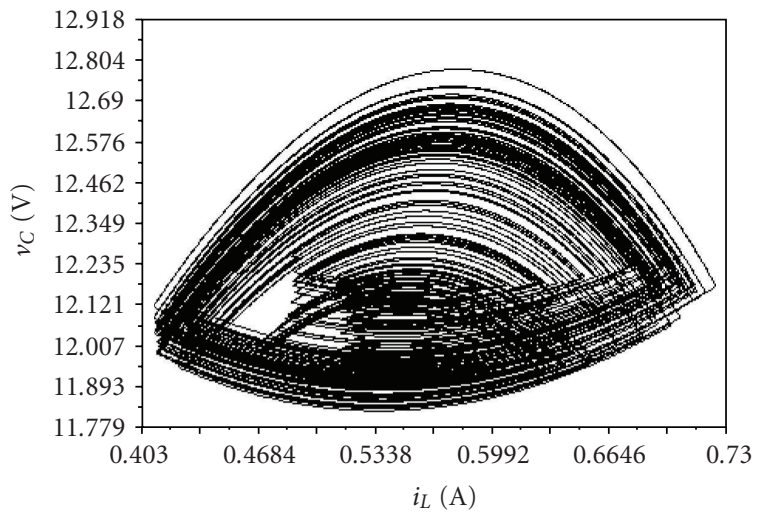

Figure 12: Chaotic regime. $(E=46.5 \mathrm{~V})$ : phase plane.

values of $E$. Figures 5 and 6 show the fundamental periodic operation. Figure 5 displays the capacitor voltage wave form, and Figure 6 gives the corresponding phase plane.

For $E=37.5 \mathrm{~V}$ and $E=41 \mathrm{~V}$, subharmonic operation has been found. Figures 7 and 8 present $2-T$ periodic subharmonic operation, whereas Figures 9 and 10 illustrate 4- $T$ periodic subharmonic operation. 
TABLe 1

\begin{tabular}{lc}
\hline$E(V)$ & $\lambda$ \\
\hline 41 & -0.0491 \\
42 & 1.2341 \\
43 & 0.9264 \\
44 & 1.1942 \\
45 & 1.1973 \\
46 & 1.8422 \\
47 & 3.8948 \\
\hline
\end{tabular}

However, the chaotic operation is given for $E=46.5 \mathrm{~V}$. Figure 11 indicates a chaotic signal with infinite order, and Figure 12 shows the phase plane $v_{C}-i_{L}$ that corresponds to a chaotic attractor. In order to qualify this chaotic behavior for beyond $E=42 \mathrm{~V}$, we have also computed the Lyapunov exponents $\lambda$ from time series for a voltage range $41-47 \mathrm{~V}$ (see Table 1).

Actually, it was shown in [9] that most controlled DC-DC converters like the voltage-mode controlled buck converter can be represented by piecewise smooth maps and such type of maps generates robust chaos, defined by the absence of periodic windows and coexisting attractors in some neighborhood of parameter space.

\section{Conclusion}

This article has illustrated a Scicos numerical study of the voltage-mode controlled buck converter that is modeled by a hybrid system. Variations of the voltage input can lead to a particular route to chaos; the system pursues a period doubling bifurcation that is interrupted by border collision after a $4-T$ periodic operation.

The purpose of studying the hybrid aspect of this circuit is to interest people working on hybrid dynamical systems domain, which may have some applications, especially, in information transmission. Also, the paper will attract the attention of readers that work with Scilab/Scicos for modeling and simulation of hybrid dynamical systems. It is true that [18] given in this paper is a good reference on this matter. However, our paper is concerned with another computational view which is the numerical study of route to chaos in a hybrid system that is different from the one studied in [18]; displaying a bifurcation diagram, for instance, is a more complex numerical study that is not included in [18].

\section{Acknowledgments}

This work is revised within a Moroccan-Spanish cooperation framework under Grant no. A/6827/06. The authors would like to thank Dr. Abdelali El Aroudi for his helpful discussions and the anonymous referees for valuable comments and suggestions. The first author Ph.D. research program is partially supported by a grant from CNRST-Morocco.

\section{References}

[1] A. El Aroudi, M. Debbat, R. Giral, G. Olivar, L. Benadero, and E. Toribio, "Bifurcations in DC-DC switching converters: review of methods and applications," International Journal of Bifurcation and Chaos in Applied Sciences and Engineering, vol. 15, no. 5, pp. 1549-1578, 2005.

[2] R. W. Brockett and J. R. Wood, "Understanding power converter chaotic behavior mechanisms in protective and abnormal modes," in Proceedings of 11th Annual International Power Electronics Conference (Powercon '84), pp. E-14-E-15, Dallas, Tex, USA, April 1984.

[3] D. C. Hamill and D. J. Jeffries, "Subharmonics and chaos in a controlled switched-mode power converter," IEEE Transactions on Circuits and Systems, vol. 35, no. 8, pp. 1059-1061, 1988.

[4] C. K. Tse, "Chaos from a buck switching regulator operating in discontinuous mode," International Journal of Circuit Theory and Applications, vol. 22, no. 4, pp. 263-278, 1994.

[5] C. K. Tse, "Flip bifurcation and chaos in three-state boost switching regulators," IEEE Transactions on Circuits and Systems I, vol. 41, no. 1, pp. 16-23, 1994.

[6] A. El Aroudi, L. Benadero, E. Toribio, and S. Machiche, "Quasiperiodicty and chaos in the DC-DC buck-boost converter," International Journal of Bifurcation and Chaos in Applied Sciences and Engineering, vol. 10, no. 2, pp. 359-371, 2000.

[7] A. El Aroudi and R. Leyva, "Quasi-periodic route to chaos in a PWM voltage-controlled DC-DC boost converter," IEEE Transactions Circuits and Systems I, vol. 48, no. 8, pp. 967-978, 2001.

[8] S. Banerjee, P. Ranjan, and C. Grebogi, "Bifurcations in twodimensional piecewise smooth maps-theory and applications in switching circuits," IEEE Transactions on Circuits and Systems I, vol. 47, no. 5, pp. 633-643, 2000.

[9] S. Banerjee, D. Kastha, S. Das, G. Vivek, and C. Grebogi, "Robust chaos-the theoretical formulation and experimental evidence," in Proceedings of the IEEE International Symposium on Circuits and Systems (ISCAS '99), vol. 5, pp. 293-296, Orlando, Fla, USA, June 1999.

[10] S. L. Campbell, J.-P. Chancelier, and R. Nikoukhah, Modeling and Simulation in Scilab/Scicos, Springer, New York, NY, USA, 2006.

[11] J. H. B. Deane and D. C. Hamill, "Instability, subharmonics, and chaos in power electronic systems," IEEE Transactions on Power Electronics, vol. 5, no. 3, pp. 260-268, 1990.

[12] M. di Bernardo, F. Garefalo, L. Glielmo, and F. Vasca, "Switching, bifurcations and chaos in DC/DC converters," IEEE Transactions Circuits and Systems I, vol. 45, no. 2, pp. 133-141, 1998.

[13] C.-C. Fang and E. H. Abed, "Harmonics balance analysis and control of period-doubling bifurcation in buck converters," in Proceedings of IEEE International Symposium on Circuits and Systems (ISCAS '01), vol. 2, pp. 209-212, Sydney, NSW, Australia, May 2001.

[14] E. Fossas and G. Olivar, "Study of chaos in the buck converter," IEEE Transactions on Circuits and Systems I, vol. 43, no. 1, pp. 13-25, 1996.

[15] Y. Ma, C. K. Tse, T. Kousaka, and H. Kawakami, "Connecting border collision with saddle-node bifurcation in switched dynamical systems," IEEE Transactions on Circuits and Systems II, vol. 52, no. 9, pp. 581-585, 2005.

[16] G. Yuan, S. Banerjee, E. Ott, and J. A. Yorke, "Border-collision bifurcations in the buck converter," IEEE Transactions on Circuits and Systems I, vol. 45, no. 7, pp. 707-716, 1998.

[17] R. Nikoukhah, "Scicos: a dynamic systems modeler and simulator," in Proceedings of the 23rd IASTED International 
Conference on Modelling, Identification, and Control (MIC '04), pp. 263-268, Grindelwald, Switzerland, February 2004, paper 412-133.

[18] R. Nikoukhah, "Modeling hybrid systems in scicos: a case study," in Proceedings of the 25th IASTED International Conference on Modeling, Indentification, and Control (MIC'06), pp. 315-319, Lanzarote, Spain, February 2006, paper 500-082.

[19] S. Pettersson and B. Lennartson, "Stability and robustness for hybrid systems," in Proceedings of the 35th IEEE Conference on Decision and Control (CDC '96), vol. 2, pp. 1202-1207, Kobe, Japan, December 1996. 

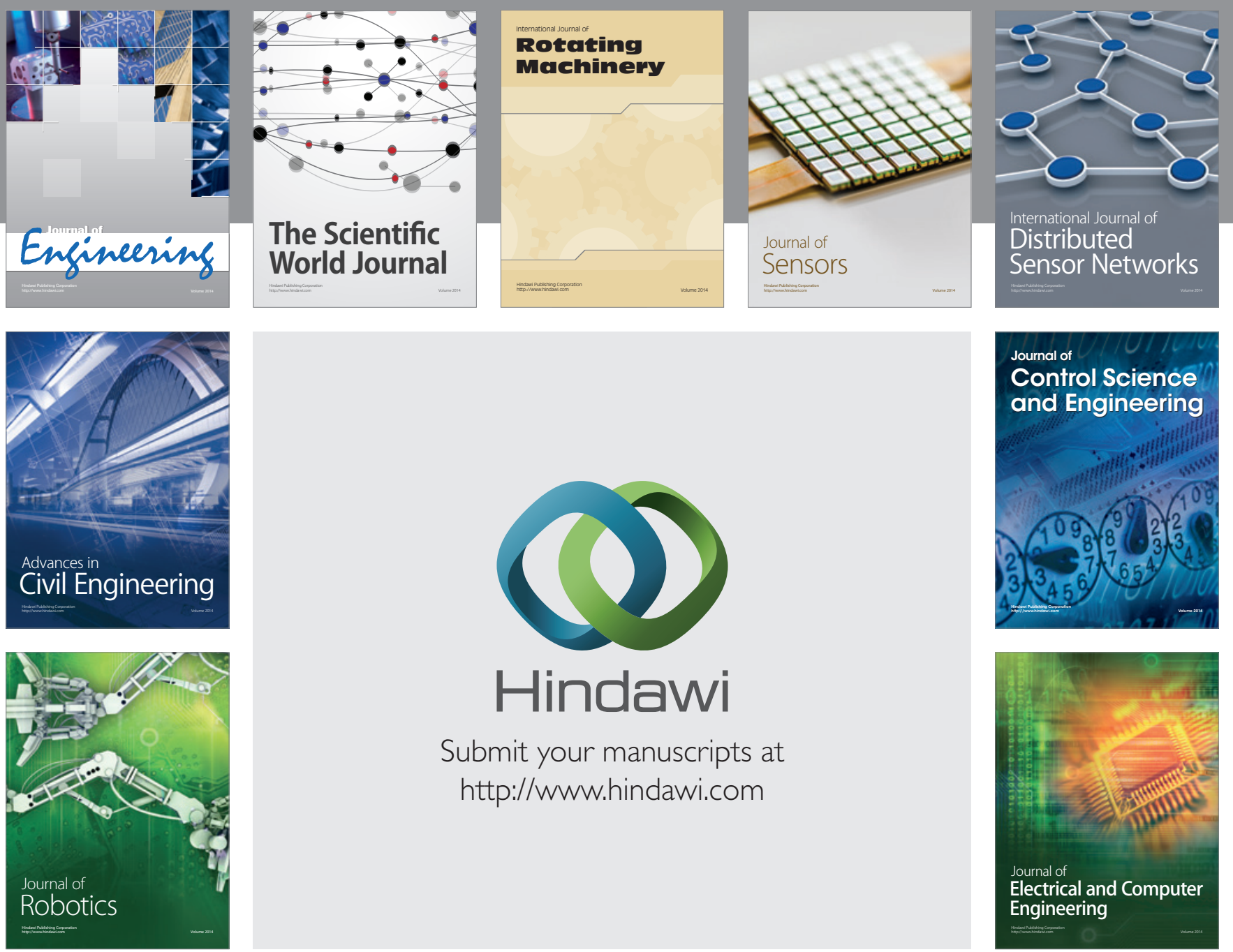

Submit your manuscripts at

http://www.hindawi.com
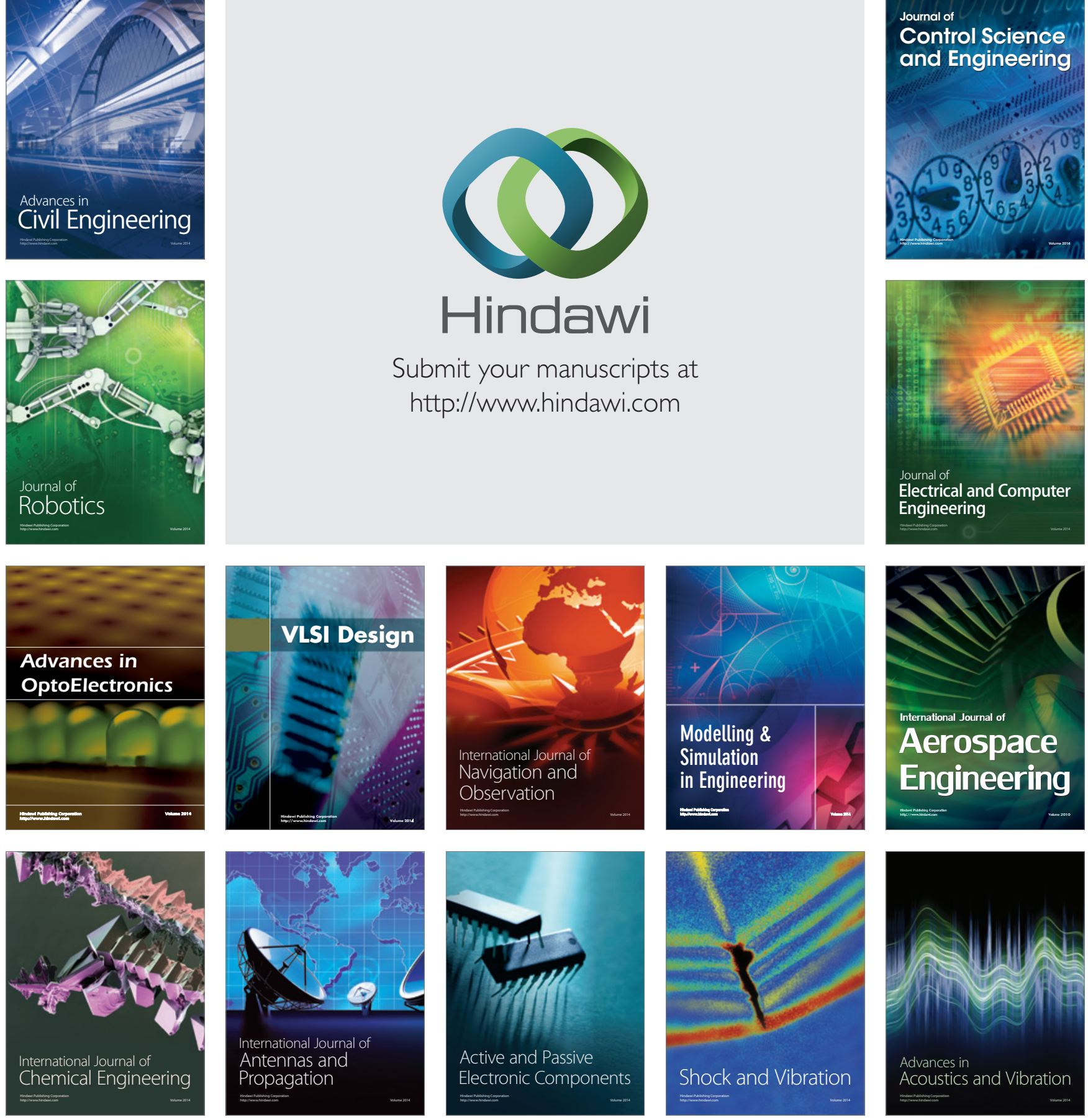